\title{
Correspondence
}

\section{Abstracts-are they really a dud currency?}

Sir,

Very few practising scientists doubt the value of the well prepared abstract as it often provides essential information. Nevertheless, as your recent editorial ${ }^{1}$ points out, many abstracts are not well prepared and can be misleading. These defects, however, are no monopoly of the abstract and are to be found equally in many full papers, particularly in journals which do not apply a system of rigorous independent review. Nevertheless, anyone with more than a passing acquaintance with leading biomedical journals must know how widely the abstract is used as a vehicle for disseminating scientific data.

It would be a pity if the quick, concise form of transmitting information provided by abstract publication were to be done away with. For those who attend the meeting where the work is presented the abstract provides a useful aide memoire, and for those unable to attend a means of learning what went on. All over the world there is an avid readership for abstracts among those who wish to know as soon as possible what is going on elsewhere. There are others, of course, who have no particular wish for this information-the editor of the Archives may be one-and for them obviously the abstract has nothing to offer.

The problem is how to monitor abstracts in order to suppress those which have been carelessly prepared while encouraging publication of those which seem to provide a good account of what was found. Two methods seem to be available. One, used by societies on both sides of the Atlantic, is to leave selection to a committee, in which case the process is inevitably secret and oligarchic. The other is for those present at the meeting, having had the opportunity both to read the abstract and to hear the paper, to vote on its suitability for publication. They can also use this opportunity to point out discrepancies or insist on corrections and insertions as a condition of publication. Although this method of vetting abstracts is far from perfect, it is open, democratic, and carries the advantage of stimulating healthy debate. In my opinion, it is much the best of all editorial devices available for judging an abstract. To criticise the voting system because it might cause embarrassment is to raise an objection which could destroy any democratic means of decision making.

Many readers and writers of abstracts will no doubt tremble to learn that they are to be totally abjured by the Archives. Even references to abstracts are to be forbidden. Nevertheless, it seems likely that the abstract habit will continue, even if the whole United Kingdom becomes an area of total abstinence-a probable event, however, only within the narrow confines of paediatrics. Surely we should aim not to suppress abstract publication but to encourage, in the various societies to which we belong, the habit of proper monitoring and criticism of abstracts. A meeting is probably not worth attending if no steps are taken to guarantee the scientific and ethical standards of the work $\frac{\bar{\sigma}}{\overline{\frac{\sigma}{D}}}$ presented and to ensure that this is properly reflected in $\frac{\omega}{\supset}$ any associated publications. To say that many meetings $\stackrel{\square}{\Omega}$ and abstracts fail to meet these standards is only to repeat what we already know very well-that in all branches of $\omega$ medicine many meetings and many publications are of an $\vec{\circ}$ unsatisfactory standard. I submit that this situation is $\overrightarrow{\vec{\omega}}$ unlikely to be remedied by abolishing the abstract, which $\vec{\omega}$ has just as much chance of being good or bad as any other form of publication.

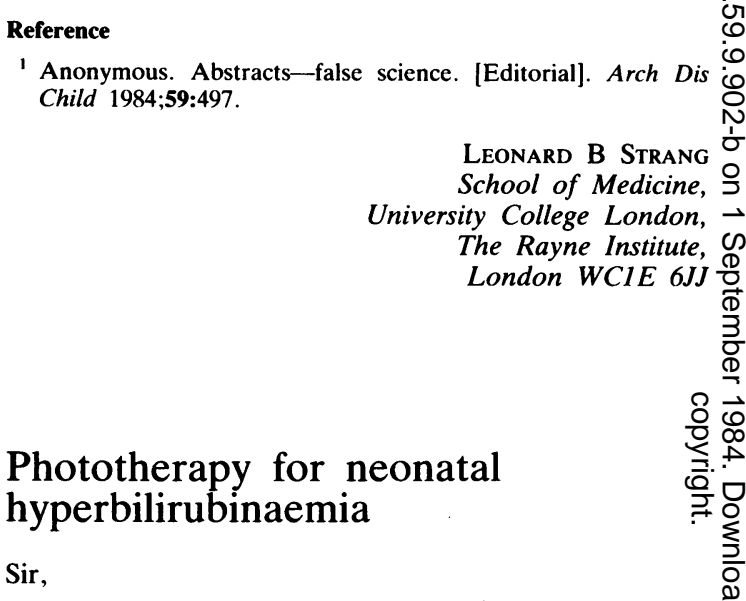

We read the article by Modi and Keay ${ }^{1}$ with interest. We would, however, question the minimal irradiance of $\varrho$ $1 \mathrm{~mW} / \mathrm{Cm}^{2}$ at 420 to $480 \mathrm{~nm}$ recommended by the authors. It $\overrightarrow{\vec{O}}$ has been shown that wave lengths between 350 and $450 \mathrm{~nm} \frac{0}{3}$ are carcinogenic and mutagenic. ${ }^{2}$ If irradiance could be increased for a spectral output of 460 to $480 \mathrm{~nm}$ it would be clinically effective without the DNA modifying effects. ${ }^{3}$ While we are in full agreement with providing the optimal dose of phototherapy in the treatment of neonatal ? hyperbilirubinaemia, we feel that the long term mutagenic effects should be taken into consideration.

$S$ M PARIDA AND A NANDA SCB Medical College, Cuttack 753007, 음

Orissa India

Drs Modi and Keay comment:

The kinetics and potential toxicity of phototherapy in $N$ human infants are by no means fully understood. Neither $\mathrm{N}$ the most appropriate wavelengths nor the optimal irradiance are known. Nor can in vitro studies showing potential mutagenicity be directly extrapolated to the human neonate.

Rosenstein and Ducore ${ }^{4}$ found the action spectrum for DNA strand breakage in normal human fibroblasts to 
exhibit two peaks; one at $265 \mathrm{~nm}$, consistent with DNA absorption, and the second at $450 \mathrm{~nm}$. Bilirubin absorbs maximally between 420 to $480 \mathrm{~nm}$-the blue range. Despite such evidence, few clinically adverse side effects have been reported.

Ennever $\mathrm{et} \mathrm{al}^{3}$ found the most effective wavelength for the production of $4 \mathrm{Z} 15 \mathrm{E}$ bilirubin to be $390 \mathrm{~nm}$ with an overall effective band from 350 to $470 \mathrm{~nm}$. But other types of isomerisation occur and the relative contributions of different isomerisations to the overall effect of phototherapy is unknown.

Vecchi $e t a l^{5}$ have shown that longer wavelengths in the green range result in more effective phototherapy than daylight lamps. They note that the depth of penetration of light in human skin increases with increasing wavelengths.

Clinical indications for phototherapy remain confused Obviously infants should be exposed to the minimal necessary irradiation. Until optimal conditions are defined, however, we can only reiterate our plea that paediatricians measure the 'dose' of phototherapy and that manufacturers provide emission spectra for phototherapy light sources.

\section{References}

1 Modi N, Keay AJ. Phototherapy for neonatal hyperbilirubinaemia: the importance of dose. Arch Dis Child 1983;58:406-9.

2 Bradley MO, Sharkey NA. Mutagenicity and toxicity of visible fluorescent light to cultured mammalian cells. Nature 1977;266:724.

3 Ennever JF, McDonagh AF, Speck WT. Phototherapy for neonatal jaundice: optimal wavelength of light. J Pediatr 1983;103:295-9.

${ }^{4}$ Rosenstein BS, Ducore JM. Induction of DNA strand breaks in normal human fibroblasts exposed to monochromatic, ultraviolet and visible wavelengths in the $240-546 \mathrm{~nm}$ range. Photochem Photobiol 1983;38:51-5.

5 Vecchi C, Dinzelli GP, Migliorini MG, Sbrana G. Green light in phototherapy. Pediatr Res 1983;17:461-3.

\section{Oral rehydration solutions and electrolyte content of water}

Sir,

We read with interest the annotation by Tripp and Candy on oral rehydration solution. ${ }^{1}$ We would, however, like to draw attention to the composition of the most vital part of oral rehydration solution-water.

In industrialised countries it is taken for granted that the electrolyte content of drinking water is negligible (as per public health standards). The composition of fresh water, however, depends upon many geological factors and varies from area to area. ${ }^{2}$

In Benghazi the sodium content of unboiled drinking water ranges from 20 to $56 \mathrm{mmol}(\mathrm{mEq}) / 1$ and that of boiled water from 39 to $82 \mathrm{mmol}(\mathrm{mEq}) / 1$. $^{3}$ The sodium content of a standard commercial formula milk, reconstituted with boiled water can range from 43 to 125 $\mathrm{mmol}(\mathrm{mEq}) / 1$ with an osmolality from 350 to over 426 $\operatorname{mmol}(\mathrm{mEq}) / 1$ (see Table).
Table Composition of natural unboiled fresh water

\begin{tabular}{lll}
\hline & Natural fresh water & Benghazi water \\
\hline Sodium $(\mathrm{mmol}(\mathrm{mEq}) / \mathrm{l})$ & $0 \cdot 35-() \cdot 72$ & $20-56$ \\
Potassium $(\mathrm{mmol}(\mathrm{mEq}) / \mathrm{l})$ & $0 \cdot 20$ & $0 \cdot 36-0) \cdot 66$ \\
Calcium $(\mathrm{mmol} /)$ & $0 \cdot 03-0 \cdot 16$ & $1 \cdot 53-2 \cdot 08$ \\
Total solids $(\mathrm{mg} / \mathrm{dl})$ & $\leqslant 0 \cdot 03$ & $0 \cdot 12-0.35$ \\
pH & $5-7$ & $7 \cdot 4-7 \cdot 74$ \\
\hline
\end{tabular}

Conversion-SI to traditional units: calcium $1 \mathrm{mmol} / \mathrm{l} \approx 4 \mathrm{mg} / 100 \mathrm{ml}$.

In view of the above limitations, we do not advocate use of any commercial or World Health Organisation oral rehydration solution in infants with diarrhoeal disease in our area. We have been treating these children successfully with water supplemented with glucose, potassium, and bicarbonate.

Paediatricians working in the developing countries or remote rural areas, should ascertain the electrolyte content of the regional drinking water before making any protocols for oral rehydration treatment.

\section{References}

1 Tripp JH, Candy DCA. Oral rehydration fluids. Arch Dis Child 1984;59:99-101.

2 Gloyna EF, Eckenfelder WW, Jr, (eds). Muncipal reuse of water. In: Water quality improvements by physical and chemical processes. Texas: University of Texas Press, 1970; tables 3 and $17,35-7,259$.

${ }^{3}$ Mir NA, Rehman SA, Chandermoulia K, Elzouki A. Electrolyte content of Benghazi water and its safety value for young infants. Garyounis Medical Journal 1981;4:27-32.

Nisar A Mir and A Y Elzouk Faculty of Medicine, University of Benghazi, Libya

\section{Doxapram and neonatal apnoea}

Sir,

Stimulated by the report of Sagi et $a l^{1}$ on the beneficial effect of doxapram in treating neonatal apnoea refractory to aminophylline, we recently used the drug in two preterm infants. The first, a baby of 28 weeks' gestation weighing $1200 \mathrm{~g}$, was 17 days old at the time of receiving doxapram. The second baby was of 26 weeks' gestation, weighed $880 \mathrm{~g}$, had suffered an intraventricular haemorrhage at the age of 24 hours, and was being ventilated for apnoea at 13 days of age. In both babies the frequency of apnoeic attacks was dramatically reduced within a few hours of starting doxapram infusion at a dose of $2.5 \mathrm{mg} / \mathrm{kg} / \mathrm{hour}$, and within the ensuing 12 hours the second baby no longer required ventilation. Both babies became extremely agitated, however, while receiving doxapram, exhibiting virtually continuous erratic limb movements, excessive crying, and disturbed sleep. We felt obliged to stop the infusion and their behaviour returned to normal within two or three hours. As in the cases reported by Sagi et al, 